\title{
Study on Wellbore Stability and Instability Mechanism in Piedmont Structures
}

\author{
Qiang Tan ${ }^{1, *}$, Baohua $\mathrm{Yu}^{1}$, Jingen Deng ${ }^{1}$, Kai Zhao ${ }^{2}$ and Jianguo Chen ${ }^{1}$ \\ ${ }^{1}$ State Key Laboratory of Petroleum Resource and Prospecting, China University of Petroleum, Beijing, 102249, China; \\ ${ }^{2}$ Petroleum Engineering Institute, Xi'an Shiyou University, Xi'an, Shanxi Province, 710065, China
}

\begin{abstract}
Piedmont tectonic belts are rich of oil and gas resources, however the intense tectonic stress and broken formation may cause great drilling problems in piedmont structures such as borehole collapse, lost circulation and gas cutting. Through analysis of in situ stress properties, bedding structure and mechanical characteristics, wellbore instability mechanism was expounded from rock mechanics, chemistry of drilling fluid and drilling technology. The high tectonic stress, formation strength decreasing and fluid pressure rising after mud filtrate seepage are main reasons for borehole collapse. The methods of calculating collapse and fracture pressure and determining drilling safety density window were put forward based on mechanical analysis. In order to reduce drilling problems in piedmont structures, some countermeasures should be taken from optimizing well track and casing program, using proper mud density, improving inhibitive and sealing ability of drilling fluid. Good sealing ability can reduce seepage and cut off pressure transmission, enhancing the effective support force. This is the key technology of maintaining wellbore stability in hard brittle shale in piedmont structures.
\end{abstract}

Keywords: Collapse pressure, instability mechanism, leakage pressure, piedmont structure, wellbore stability.

\section{INTRODUCTION}

Piedmont structure refers to the transition zones from the mountain to the plain, which is the product of intense tectonic movements. Piedmont tectonic belts are rich of oil and gas resources in southern margin of Junggar Basin, Qaidam Basin, Tarim Basin, Tuha basin, the northeast of Sichuan in China. With the exploration and development of piedmont tectonic belts, the number of drilling is increasing, and problems of borehole instability also stand out during drilling.

Piedmont structures are characterized with intense tectonic stress, high dip angle, and lots of faults. High abnormal formation pressure is often observed. Another outstanding feature is that there are a large number of borehole instability problems during drilling in piedmont structures. For example, when wells were drilled in piedmont structure of Junggar Basin, borehole diameter enlarged more than 50\% in a lot of well sections, which had serious impact on logging and cementing quality [1]. Another example is in the northeast area of Sichuan province, where the structure is affected by three directions of tectonic stress, and it had serious problems such as lost circulation, borehole collapse, enlargement and so on in the high and steep formations drilling, which affected efficiency of exploration and development seriously. In general, there are many problems that need to be solved such as borehole collapse, frequent gas cut and overflow and lost circulation etc during drilling in piedmont structures [2]. Severe borehole instability is harmful to engineering safety, drilling quality and cost controlling, so more attention must be paid and controlled by technological means.

*Address correspondence to this author at the State Key Laboratory of Petroleum Resource and Prospecting, China University of Petroleum, Beijing, 102249, China; Tel: 0086-010-89739161; Fax: 0086-010-89733911;

E-mails: tanqiang_cup@126.com, $\tan 1980 @ 126 . c o m$
The main complex problems of piedmont structures in drilling are as follows:

(1) Lost circulation. Lost circulation problem is often encountered for drilling in most piedmont structures, causing fast leakage and large leakage amount and it is difficult to be solved [3-5].

(2) Borehole collapse. Affected by geological and formation characteristics of piedmont structures, wellbore is prone to collapse, which causes borehole diameter enlarged seriously or drill pipe sticking during drilling $[6,7]$.

(3) Gas cutting and overflow. Piedmont structures are affected by extrusion stress, so there is higher abnormal formation pressure generally [8-11]. Therefore, high density drilling fluid is necessary to balance the pore pressure, otherwise it's easy to cause gas cut and overflow problems.

The lost circulation, gas cutting and collapse problems relate to each other, and lead to drilling safety accidents possibly. Drilling fluid level decreases due to serious leakage, so that fluid column pressure is not able to balance the pore pressure or collapse pressure, which lead to gas cut and well kick problems, or borehole collapse and pipe sticking accidents. At the same time, when gas cutting and hole collapse occurs, it generally needs to increase the density of drilling fluid, which is easy to cause leakage again. Therefore, it is necessary to analyze instability mechanism and take appropriate countermeasures to solve potential safety hazard in piedmont structures drilling.

\section{BOREHOLE INSTABILITY MECHANISM IN PIEDMONT STRUCTURES}

\subsection{The In Situ Stress Characteristics}

Most of piedmont structures are controlled by thrust fault and sustained by strong ground stress. According to the An- 
derson's classification based on relative magnitude of formation principal stresses in different structures, the magnitude of three principal stresses in thrust fault controlled structure is: maximum horizontal principal stress $>$ minimum horizontal principal stress $>$ vertical principal stress $[12,13]$. However, in many in situ stress tests the vertical principal stress is generally intermediate principal stress, and the minimum horizontal principal stress approximately is equal to or slightly less than the vertical principal stress in piedmont structures. For example, the principal stress test and calculation results in Xujiahe group formation of western Sichuan structure [14] and the experimental results of Kaiser effect of Huo'erguosi anticline [15] and so on conform to the law "maximum horizontal principal stress $>$ minimum horizontal principal stress > vertical principal stress".

Affected by strong tectonic stress, there are lots of faulted structures in piedmont area, which makes wellbores easy to breakout, and is detrimental to drilling.

\subsection{Rock Structure and Mechanical Characteristics of Piedmont Structures}

Shale formation is the most prone to borehole collapse instability. According to statistics, about $90 \%$ of the borehole instability problems occurred in shale formation [16]. Relatively speaking, the lithology of formations prone to leakage is more complex. Lost circulation may occur in high porosity and high permeability sandstone, sand shale interface, fractured shale and carbonate formation etc.

Due to the strong tectonic geo-stress, a typical characteristic of piedmont structures is bedding, fractures and cracks development, which makes borehole to be prone to spall. Fig. (1) shows hard brittle shale cores from piedmont structure, where macroscopic stratification planes are obvious. Micro cracks can be seen also in the cores with scanning electron microscope (Fig. 2).

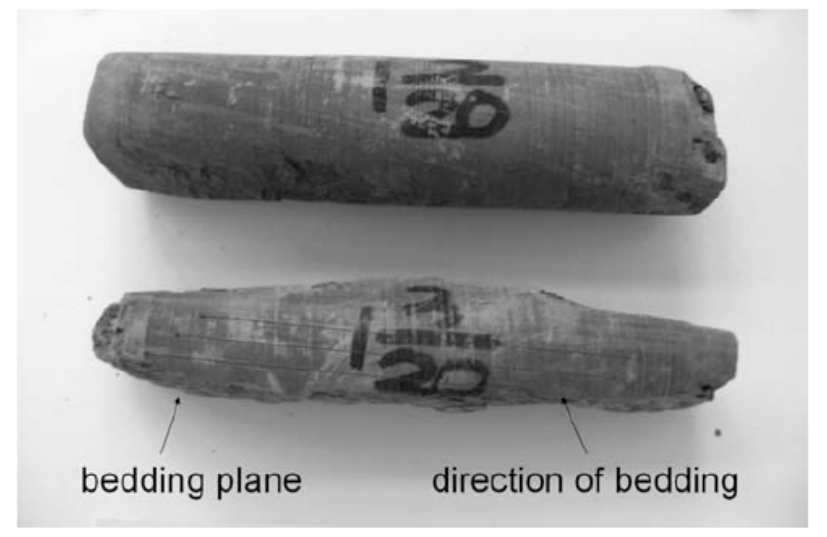

Fig. (1). The bedding plane in hard brittle shale of piedmont structures.

Anisotropy of mechanical properties is obvious in hard brittle shales in piedmont structures. Chenevert's research results show that compressive strength of this type of shale is the function of the angle between axial stress and bedding planes. When the angle is between $45^{\circ}$ and $75^{\circ}$, the compressive strength is only $20 \%$ of that loading perpendicular to the bedding planes [17].

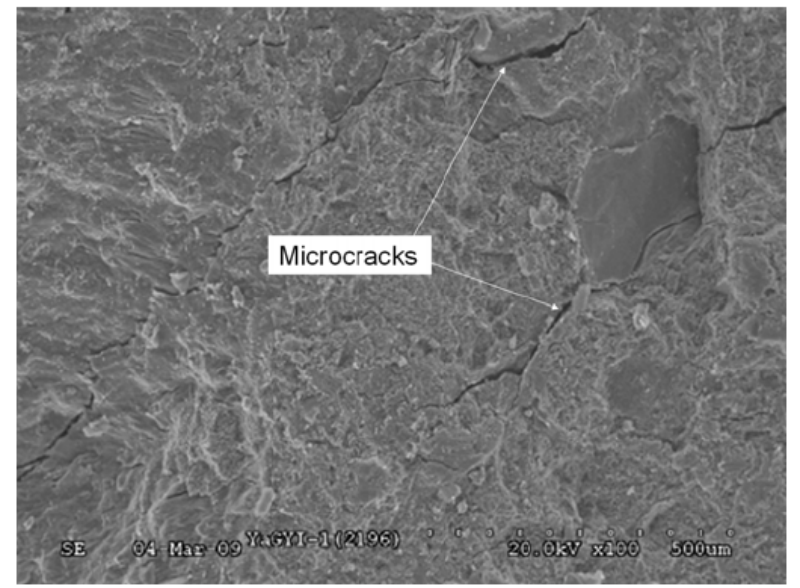

Fig. (2). The scanning electron microscope photographs of hard brittle shale of piedmont structures (boost 100 times).

In addition to the effect of bedding and cracks on mechanical properties, it is a main pathway of drilling fluid seepage. Seepage will reduce rock strength, and the borehole will be easier to collapse and instable [18].

\subsection{Mechanism Analysis of Borehole Instability in Pied- mont Structures}

There are three aspects that affect borehole collapse instability in piedmont structures which are rock mechanics, drilling fluid and drilling technology.

\section{(1) Rock mechanics}

Due to the severe tectonic stress, wellbore collapse pressure is high. If the density of drilling fluid is too low to balance the collapse pressure, borehole spalling and caving will take place. And because of the bedding and cracks in formation, breaking from weak planes is the main form of borehole caving.

\section{(2) Drilling fluid chemical characters}

Adverse impact will generate when drilling fluid filtrate invades the formation. On the one hand, it will reduce the formation strength, and further weaken the strength of weak plane in hard brittle shales, which makes softening zone to be formed around the borehole. On the other hand, pressure transfer will happen, which increases pore pressure near the borehole and reduces the effective stress, causing wellbore instability easily.

\section{(3) Drilling technology}

Too fast pipe running results in pressure surge or high swab pressure. Downhole pressure fluctuation is easy to induce relatively loose rock to spall in the borehole. And drilling pipes and tools will crash and scratch with borehole wall during trip, which is easy to make wellbore collapse.

There are two common reasons for frequent leakage or lost circulation during drilling in piedmont structures. One is that formation is broken and full of leakage paths in piedmont structures. As long as there is a positive differential pressure, leakage or lost circulation may occur during drilling. The other reason is because of high pore pressure and collapse pressure. High density drilling fluid must be used to 
balance the pressure in drilling, and ECD is easy to be higher than leakage pressure, which makes leakage or lost circulation to occur.

\section{CALCULATION METHOD OF BOREHOLE STA- BILITY IN PIEDMONT STRUCTURES}

\subsection{A Model for Calculating the Collapse and Leakage Pressure}

The quantitative target of wellbore stability analysis is to get the upper and lower limit of drilling fluid density. The upper limited density is determined by leakage pressure, while lower limited density is determined by pore pressure or collapse pressure.

There are a large number of structure surfaces in piedmont structures, such as bedding planes, fractures, micro cracks, and so on. These surfaces make formations as discontinuous rock mass, so the borehole stability questions should be solved by numerical methods such as discrete element methods. However, numerical analysis methods are complex, and in drilling engineering some assumptions are made to use equivalent continuum model for solving the questions simply to reduce the computing time.

Effected by in-situ stress and drilling fluid column pressure, the stress distribution around borehole can be solved using the linear elastic plane strain method. When borehole axis is perpendicular or close to perpendicular to the bedding plane, the effect of formation anisotropic properties to stress distribution is negligible [19].

Stress distribution in three direction on vertical wells borehole wall can be calculated by:

$$
\left\{\begin{array}{l}
\sigma_{r}=p_{i} \\
\sigma_{\theta}=-p_{i}+(1-2 \cos 2 \theta) \sigma_{H}+(1+2 \cos 2 \theta) \sigma_{h} \\
\sigma_{z}=\sigma_{v}-\mu\left[2\left(\sigma_{H}-\sigma_{h}\right) \cos 2 \theta\right]
\end{array}\right.
$$

Considering drilling fluid seepage, the additional stresses on borehole wall are:

$$
\left\{\begin{array}{l}
\sigma_{r r}=-f\left(p_{i}-p_{p}\right) \\
\sigma_{\theta \theta}=\sigma_{z z}=(\xi-f)\left(p_{i}-p_{p}\right)
\end{array}\right.
$$

Because hydration swelling of hard brittle shale is weak, the hydration stress can be neglected.

If Mohr-Coulomb criterion is used as failure criterion in calculation, and formation strength loss and additional stress caused by drilling fluid seepage is considered, the calculation formula of collapse pressure can be written as follows [20]:

$$
p_{c}=\frac{\eta\left[3 \sigma_{H}-\sigma_{h}-(\xi-f) p_{p}\right]+K^{2} p_{p} f-2 C K}{(1-\alpha+f) K^{2}-\eta(\xi-f-1-\alpha)}
$$

At the same time, considering the existing weak planes in piedmont structures, a judgment method of single weak plane criterion should be used in weak planes for describing shearing instability. The single weak plane criterion is shown below [21]:

$$
\sigma_{1}^{\prime}-\sigma_{3}^{\prime}=\frac{2\left(C_{w}+\mu_{w} \sigma_{3}^{\prime}\right)}{\left(1-\mu_{w} \cot \beta\right) \sin 2 \beta}
$$

Under the condition of formation stress, whether MohrCoulomb criterion or weak plane failure criterion is met, it means shear failure occurred around the borehole formation. In general, when the angle of borehole axis and bedding plane normal is smaller, Mohr-coulomb criterion plays a main role, otherwise weak plane criterion plays a mayor role.

Lost circulation is a common phenomenon in piedmont structures. Lost circulation problems may be caused by fracturing formation or reopening of primary fractures. The calculation formula of fracture pressure using tensile failure criteria is:

$$
p_{f}=\frac{3 \sigma_{h}-\sigma_{H}-(\alpha \xi-f) p_{p}+S_{t}}{1+\alpha(1-\xi)+f}
$$

There are many fractured leakage paths in piedmont structures. After the drilling fluid flows into these fractures, fractures extension and leakage will occur if fluid column pressure overcomes minimum horizontal principal stress. Consequently the leakage pressure is equal to the minimum horizontal principal stress that is considered as upper limitation of drilling fluid density.

So the leakage pressure in piedmont structures can be defined as:

$$
p_{l}=\min \left[\sigma_{h}, \frac{3 \sigma_{h}-\sigma_{H}-(\alpha \xi-f) p_{p}+S_{t}}{1+\alpha(1-\xi)+f}\right] .
$$

In general, there is abnormal high pressure in piedmont structures, and proper drilling fluid density must be used to balance formation pressure during drilling. Therefore, the choice of safe drilling fluid density need consider pore pressure, collapse pressure and leakage pressure.

\subsection{Application Example}

Abnormal high pressure was encountered in a vertical well drilling in some piedmont structure, and due to the effect of strong tectonic stress and formation breaking, borehole collapse and leakage became serious problems. In the process of drilling, gas kick, borehole collapse and lost circulation appeared at the same time. Compared to logging data, borehole collapse was mainly located in mudstone interval, and lost circulation was mostly located in sand and mudstone interbedding.

In this structure, average dip angle is about 30 degrees, and the dip direction is $\mathrm{N} 90^{\circ} \mathrm{E}$. Rock mechanics parameters can be calculated by the following models [22, 23]:

$$
\left\{\begin{array}{l}
\sigma_{c}=4.5 E\left(1-V_{c l}\right)+8 E V_{c l} \\
C=-0.417+0.289 \sigma_{c}-0.000519 \sigma_{c}^{2} \\
\phi=57.8-105 f
\end{array}\right.
$$

The overburden pressure can be calculated through formation density integral. Horizontal principle stresses calculation model is: 


$$
\left\{\begin{array}{l}
\sigma_{H}=\left(\frac{\mu}{1-\mu}+\omega_{1}\right)\left(\sigma_{V}-\alpha p_{p}\right)+\alpha p_{p} \\
\sigma_{h}=\left(\frac{\mu}{1-\mu}+\omega_{2}\right)\left(\sigma_{V}-\alpha p_{p}\right)+\alpha p_{p}
\end{array}\right.
$$

According to leak off test and regional law of in-situ stress, tectonic stress factors are respective 0.9 and 1.2. Parameters of in-situ stresses and rock mechanics of vertical depth $3000 \mathrm{~m}$ are shown in Table $\mathbf{1}$.

Table 1. Formation parameters of vertical depth $3000 \mathrm{~m}$.

\begin{tabular}{|c|c|}
\hline Items & Values \\
\hline \hline Overburden pressure $\sigma_{V}$ & $69.0 \mathrm{MPa}$ \\
\hline Maximum horizontal principal stress $\sigma_{H}$ & $73.5 \mathrm{MPa}$ \\
\hline Minimum horizontal principal stress $\sigma_{h}$ & $61.5 \mathrm{MPa}$ \\
\hline Pore pressure $p_{p}$ & $51 \mathrm{MPa}$ \\
\hline Elastic modulus $E$ & $9 \mathrm{GPa}$ \\
\hline Poisson's ratio $\mu$ & 0.25 \\
\hline Cohesion $C$ & $18 \mathrm{MPa}$ \\
\hline Inter friction angle $\phi$ & 0.61 \\
\hline Cohesion of weak planes $C_{w}$ & $10 \mathrm{MPa}$ \\
\hline Friction angle of weak planes $\phi_{w}$ & 0.49 \\
\hline Porosity $f$ & 0.30 \\
\hline Effective stress coefficient $\alpha$ & 0.80 \\
\hline
\end{tabular}

The safe density window of vertical wells in this structure was calculated based on logging data using the model mentioned in Section 3.1, and is shown in Fig. (3).

In order to maintain the mechanics balance in drilling, the drilling fluid column pressure should be located in the safe density window in theory. Nevertheless in piedmont structures, drilling safe density window is very narrow, and when the easy leakage formation, high pressure formation and easy collapse formation are at the same borehole section, it is difficult to fully meet the mechanical stability requirements. Therefore, it needs to take corresponding measures to stabilize borehole, and ensure drilling safety from the rock mechanics, drilling design and drilling fluid chemistry.

\section{ENGINEERING COUNTERMEASURES OF BORE- HOLE STABILITY IN PIEDMONT STRUCTURES}

In consideration of various and serious drilling problems in piedmont structures, we must put forward higher request in drilling fluid density and performance, well trajectory, and casing program etc. according to results of borehole stability analysis before and during drilling. The main purpose is to maintain borehole stability and reduce possible complex problems.

(1) Select proper drilling fluid density. Due to the narrow safe density window, the main principle of drilling fluid density selection is balancing formation pressure and with no overflow in order to prevent lost circulation. For the high collapse pressure intervals, drilling fluid density should be increased appropriately, but the premise is that drilling fluid has good sealing ability.

(2) Improve the inhibition and plugging of drilling fluid. Improving drilling fluid inhibition is good to prevent hydration swelling of shales. The main purpose of improving plugging property is to reduce the effect of drilling fluid flowing into formations. If the plugging property is bad, fluid pressure transmission will speed up in bedding or fracture formations, enhancing drilling fluid density an adverse effect to stabilize borehole.

(3) Improve the cuttings-carrying ability of drilling fluid. The safe drilling fluid density window is narrow in piedmont structures. In order to avoid lost circulation, wellbore breakout in certain sections is inevitable. Therefore, drilling fluid must have a good ability of cuttingscarrying so that it can carry out collapsed blocks from

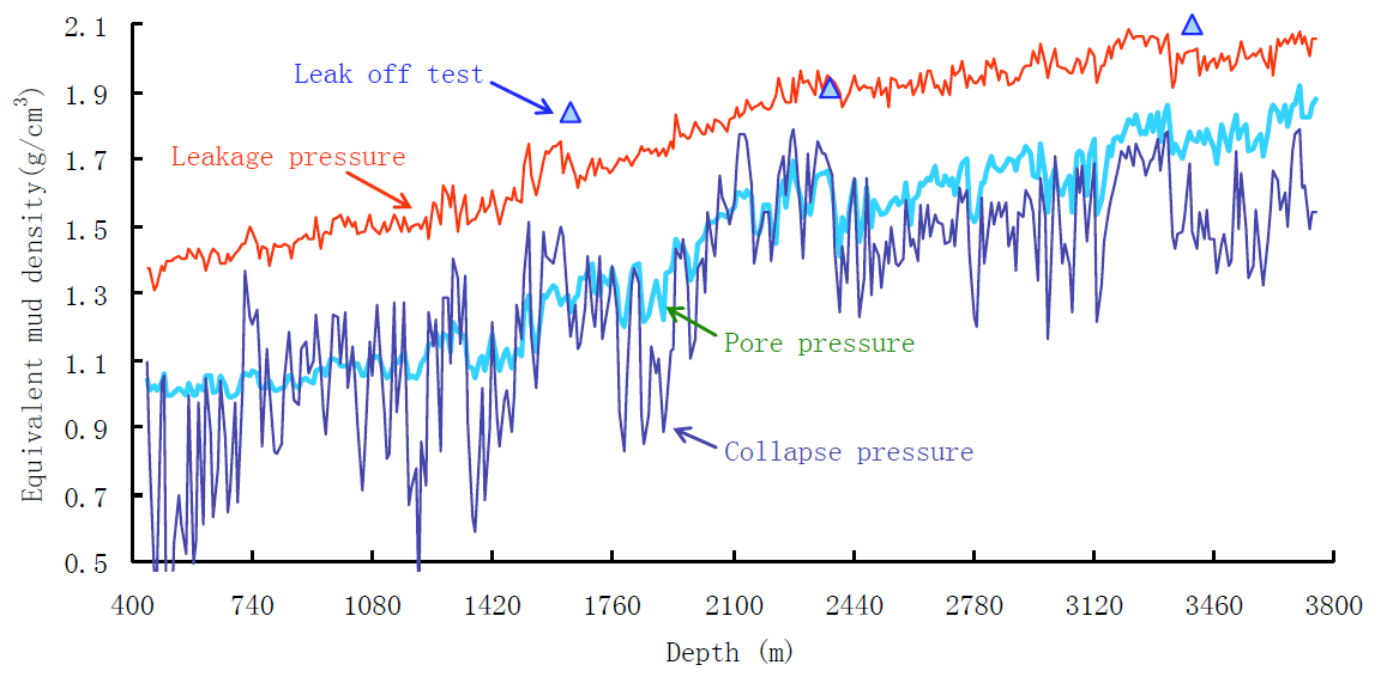

Fig. (3). Analysis results of drilling safe density window in some piedmont structure. 
downhole to the ground surface timely, which can prevent downhole blockage, and at the same time can also reduce the equivalent circulating density to prevent leakage.

(4) Optimize well track design. In bedding shale formations, if the angle between borehole axis and bedding plane normal is more than $40^{\circ}$, the borehole is most easy to collapse, while borehole axis is perpendicular to the bedding planes, borehole is most stable. Therefore in structures with large dip, drilling directional wells perpendicular to the bedding planes is better than drilling vertical wells.

(5) Optimize casing program. The effect on drilling fluid properties of downhole pressure and temperature should be considered in casing program design to avoid the high pore pressure formations [24], thief zones and unstable formations to locate in a same open hole section. At the same time, plugging while drilling should be done in order to improve the loading capacity of formations.

\section{CONCLUSION}

(1) The piedmont structures are affected by strong tectonic stress, and there is abnormal high pressure generally. Easily collapsed shale formations are mainly hard brittle shale, where there are weak structural planes such as bedding and cracks. These weak planes are main channel for drilling fluid seepage.

(2) Shear failure of weak planes under the condition of strong tectonic stress is a chief type of hard brittle shale in piedmont structures. Drilling fluid seepage causes the decrease of formation strength and fluid pressure transmission near borehole, which exacerbates the borehole instability.

(3) The effect of drilling fluid seepage and weak planes should be considered in collapse pressure calculation of piedmont structures. Leakage pressure is determined by the minimum horizontal principal stress mainly, while the safe density window of drilling by pore pressure, collapse pressure and leakage pressure.

(4) Some countermeasures should be taken on well trajectory and casing program design, drilling fluid density and properties to reduce drilling problems. In drilling process, using appropriate density according to safe density window, slowing drilling fluid seepage and cutting off pressure transmission by improving sealing ability of drilling fluid are key measures to sustain borehole stability effectively.

\section{LIST OF SYMBOLS}

$$
\begin{aligned}
& C=\text { Cohesion of formation, } \mathrm{MPa} \\
& C_{w}=\text { Cohesion of weak planes, } \mathrm{MPa} \\
& E \quad=\text { Young's modulus, } \mathrm{GPa} \\
& K=\text { Coefficient, } K=\cot [(\pi-2 \phi) / 4] \text {, nondimen- } \\
& \text { sional } \\
& S_{t} \quad=\quad \text { Tensile strength, } \mathrm{MPa} \\
& V_{c l} \quad=\text { Clay mineral content, } \% \\
& \alpha=\text { Effective stress coefficient, nondimensional }
\end{aligned}
$$

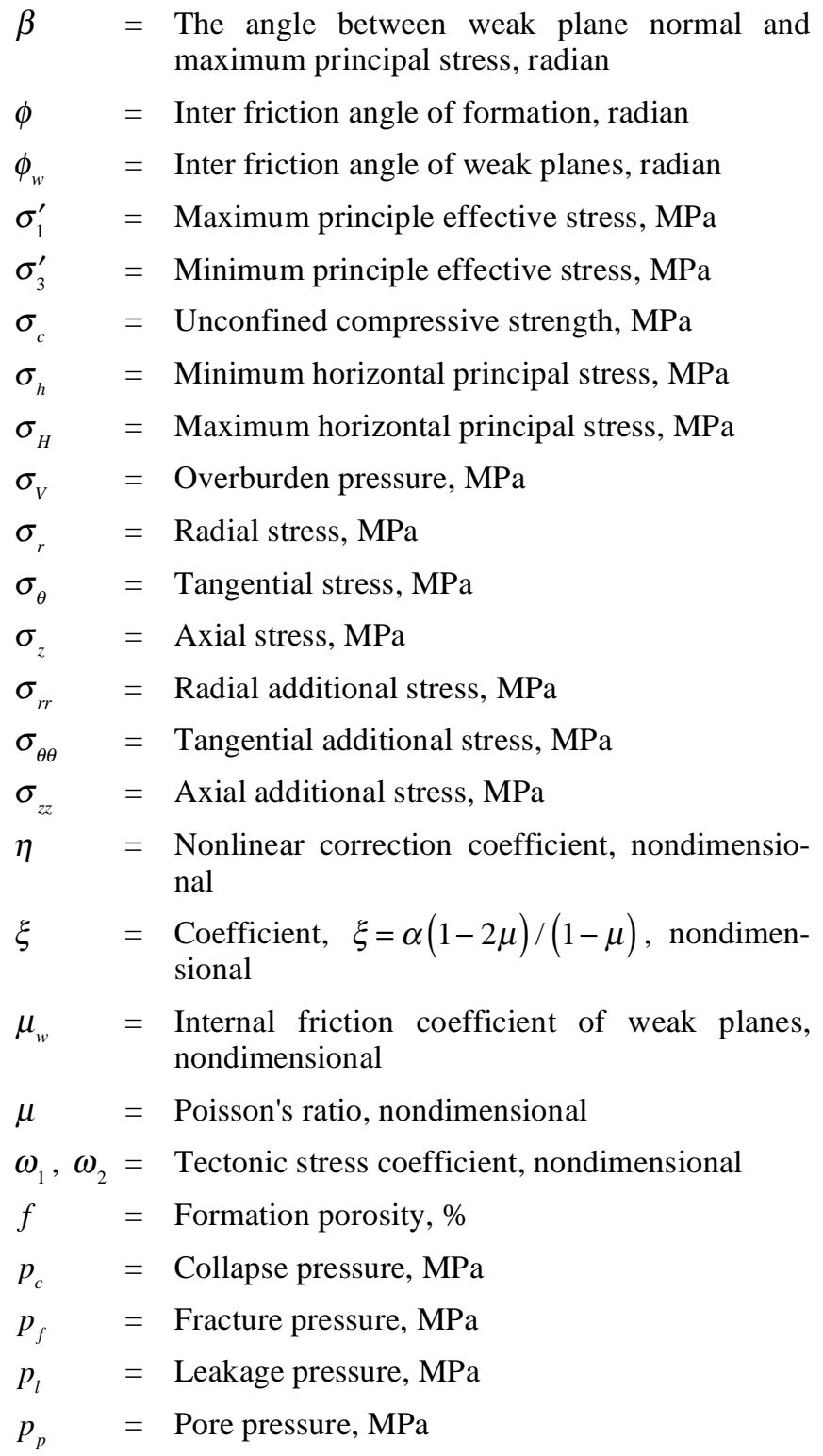

\section{CONFLICT OF INTEREST}

The authors confirm that this article content has no conflict of interest.

\section{ACKNOWLEDGEMENTS}

This work was supported by the Natural Science Foundation of China (No. 51174219), Basic Research on Drilling \& Completion of Critical Wells for Oil \& Gas (No. 51221003) and Scientific Research Program Funded by Shaanxi Provincial Education Department (No.14JK1583).

\section{REFERENCES}

[1] R. Liu, and Y. Zeng, Technical Difficulties and Countermeasures Under the Condition of Complex Drilling, China Petrochemical Press: Beijing, 2005.

[2] H. Wang, and X. Zheng, "Status quo and faced challenges of deep well drilling techniques of petro china", Oil Drilling \& Production Technology, vol. 27, pp. 4-8, 2005.

[3] X. Shi, J. Xiong, P. Chen, H. Xia, and Z. Cai, "Study on the lost circulation and sealing mechanism in complex high dip crack for- 
mation", Drilling \& Production Technology, vol. 30, pp. 24-26, 2007.

[4] Y. Li, X. Ge, Y. Zhang, and H. He, "Location and property determination of loss zone with electric imaging log", Well Logging Technology, vol. 31, pp. 57-60, 2008.

[5] B. Hou, M. Chen, H. Lu, B. Zhang, H. Yang, and H. Hao, "Cause analysis of lost circulation and plugging method in paleogene of Kuqa piedmont structure", Oil Drilling \& Production Technology, vol. 31, pp. 40-44, 2009.

[6] W. Zeng, J. Zheng, C. Feng, and X. Hu, "Drilling technology of highly difficult deep wells in piedmont structure in the southern margin of Junggar basin”, Natural Gas Industry, vol. 20, pp. 44-47, 2000.

[7] S. Liu, "Drilling Fluid technology of complex formation in piedmont structure in the southern margin of Junggar basin", Petroleum Drilling Techniques, vol. 31, pp. 33-34, 2003.

[8] G. Gao, Z. Huang, Z. Wang, and Y. Quan, "Study on the mechanism of the formation of formation abnormal high pressure", Journal of Xi 'an Shiyou University (Natural Science Edition), vol. 20, pp. 1-7, 2005.

[9] Y. Zhu, X. Shao, S. Yang, Y. Jiang, C. Liu, and B. Li, "Character and origin of overpressure in Kela-2 gas field", Journal of Southwest Petroleum Institute, vol. 22, pp. 9-13, 2000.

[10] G. Liu, and Y. Wang, "Vertical pressure structure and genetic mechanism of overpressure in Kuqa depression, the Tarim basin", Natural Gas Industry, vol. 26, pp. 29-31, 2006.

[11] M. Li, Z. Li, and J. Liao, "Analysis of ground stress in the southern part of Jungger basin and discussions of the related issues", Xinjiang Geology, vol. 23, pp. 343-346, 2005.

[12] M.A. Addis, N.C. Last, and N.A. Yassir, "Estimation of horizontal stresses at depth in faulted regions and their relationship to pore pressure variations", SPE Formation Evaluation, vol. 11, pp. 1118, 1996.

[13] A. Jain, A.K. Verma, V. Vishal, and T.N. Singh, "Numerical simulation of fault reactivation phenomenon", Arabian Journal of Geosciences vol. 6, pp. 3293-3302, 2012.
[14] K. Tong, "Research and Application of In-Situ Stress Characteristics of Deep Xujiahe Formation in West Sichuan Depression", M. S. thesis, Chengdu University of Technology, Chengdu, ON, China, 2009.

[15] Y. Liu, H. Yang, and P. Deng, "In-situ stress research of wellblock Huo-10 in Huo'erguosi anticline in Junggar basin", Xinjiang Petroleum Geology, vol. 29, pp. 504-506, 2008.

[16] R. P. Steiger, and P. K. Leung, "Quantitative determination of the mechanical properties of shales", SPE Drilling Engineering, vol. 7, pp. 181-185, 1992.

[17] M.E. Chenevert, and C. Gatlin, "Mechanical anisotropies of laminated sedimentary rocks", In: The $39^{\text {th }}$ Annual Fall Meeting of SPE, 1964, pp. 67-77.

[18] B. Yu, J. Deng, and H. Wang, "Borehole stability technique for Huo'erguosi anticline, Junggar basin, Norhtwest China", Petroleum Exploration and Development, vol. 34, pp. 108-112, 2007.

[19] M. Chen, Y. Jin, and G. Zhang, Petroleum Engineering Rock Mechanics. Science Press: Beijing, 2008.

[20] Y. Lou, and Y. Jin, Rock Mechanics and Petroleum Engineering. Petroleum Industry Press: Beijing. 2006.

[21] Y. Zheng, and H. Liu, "Mechanics of weak plane body (weak interlayer body) - a methods of rock mass mechanics", Hydrogeology and Engineering Geology, vol. 7, pp. 6-12, 1981.

[22] C. Chang, M. D. Zoback, and A. Khaksar, "Empirical relations between rock strength and physical properties in sedimentary rocks", Journal of Petroleum Science and Engineering, vol. 51, pp. 223-237, 2006.

[23] K. Sarkar, V. Vishal, and T.N. Singh, "An empirical correlation of index geomechanical parameters with the compressional wave velocity”, Geotechnical and Geological Engineering, vol. 30, pp. 469-479, 2011.

[24] Q. Su, and X. Hou, "Research on drilling design techniques for narrow mud weight window", Petroleum Drilling Techniques, vol. 39 , pp. 62-65, 2011.

(C) Tan et al.; Licensee Bentham Open.

This is an open access article licensed under the terms of the Creative Commons Attribution Non-Commercial License (http://creativecommons.org/licenses/by-nc/3.0/) which permits unrestricted, non-commercial use, distribution and reproduction in any medium, provided the work is properly cited. 